\title{
$\underline{\mathbf{P}-191}$
}

\section{Chemical Constituents and Healing Properties of Kalanchoe Pinnata Extracts}

\author{
Faridahanim Mohd Jaafar ${ }^{*}$, Nesamalar Kantasamy and Nooraain Hashim \\ Faculty of Applied Sciences, Universiti Teknologi MARA, 40450 Shah Alam, Selangor, Malaysia; \\ E-mail: faridahanim@salam.uitm.edu.my
}

Total phenolic (TPC) and steroids contents were determined from $K$. pinnata leaves. The ethanolic extract revealed a significantly higher TPC of the leaves than the petioles which were $0.8816 \mathrm{mg} / \mathrm{g} \mathrm{GAE}$ and $0.3200 \mathrm{mg} / \mathrm{g} \mathrm{GAE}$, respectively. However, the aqueous extract of both plant parts contained lower TPC as compared with the ethanolic extracts with 0.3501 $\mathrm{mg} / \mathrm{g}$ GAE for leaves and $0.3220 \mathrm{mg} / \mathrm{g}$ GAE for petioles. The dichloromethane extraction and chromatographic method were conducted to determine the steroid contents. Three steroids isolated were campesterol (ergost-5-en-ol), stigmasterol (stigma-5, 22-dien-3-ol) and $\beta$-sitoserol ((23S)-ethylcholest-5-en- $\beta$-ol). The structures of the steroids were determined using Gas Chromatography-Mass Spectrometry. Healing effect of the aqueous extract of the leaves was tested on experimental rats through oral treatment and it showed wound contractions of the treated animals was greater than those of the control group. In conclusion, $K$. pinnata has positive effect on healing properties possibly due to its TPC and steroids contents.

Keywords: Kalanchoe Pinnata, Total Phenolic Content, Steriod Content, Wound Contraction. 